\title{
Factors Predicting Mortality In Indian Patients Hospitalized For Acute Decompensated Heart Failure
}

\author{
Dr.Mpalaniappan ${ }^{1}$, Dr. N Karthikeyan ${ }^{2}$, Dr.P Praveen Kumar ${ }^{3}$, \\ Dr B Vetriveeran ${ }^{4}$, Dr T Ravikumar ${ }^{5}$, Dr P Vishnuram ${ }^{6}$, Dr. S. Usha ${ }^{7}$ \\ 1,2Assistant Professor, Dept. of Medicine, Govt. Medical College \& ESIC Hospital, Coimbatore. \\ 3 - Junior Resident in General Medicine, Coimbatore Medical college hospital, Coimbatore. \\ 4- Associate Professor, Dept. of Medicine, Govt.MedicalCollege, Dharmapuri. \\ 5- Professor, Dept. of Medicine, Govt. Medical \\ College \& ESICHospital, Coimbatore. \\ 6 - Senior Assistant Professor, Dept. of Medicine, CoimbatoreMedicalCollege, Coimbatore. \\ 7. Professor, Dept. of Medicine, Coimbatore Medical College, Coimbatore.
}

\begin{abstract}
BACKGROUND
To identify predictors of in-hospital mortality in Indian subset of patients hospitalized for ADHF and to assess various epidemiological, clinical and investigational characteristics of patients in relation to their hospital survival or non-survival. Analysis was done to estimate the characteristics that predict in-hospital mortality and to compare those mortality predictors with those of western studies.
\end{abstract}

\section{METHOD}

It is a prospective study carried out in CoimbatoreMedicalCollegeHospital from May 2016 - July 2016. A total of 100 patients who were hospitalized for ADHF were selected for the study

\section{RESULTS}

Acute decompensated heart failure is common across all age groups though more frequent in $50-70$ years age group. Poor NYHA grades are strongly associated with increased in-hospital mortality rate. Approximately three fourth of admissions is for new onset (first time) ADHF. Lower ejection fractions and hemoglobin level are correlated with higher hospital death rate. Maximum deaths occur in the initial five days of admission.The inhospital mortality rate of our study is $11 \%$.

\section{CONCLUSION}

Due to the changing pattern of risk factors, the incidence and prevalence of heart failure are on the rise especially in India. Large-scale Indian studies are needed so that management strategy and guidelines specific for Indian ADHF patients especially in resource restrained settings can be devised.

KEYWORDS : HEART FAILURE, MYOCARDIAL INFARCTION, ADHF

\section{IN. INTRODUCTION}

The estimates of prevalence and annual incidence of heart failure in India in the year 2000 are $1.3-4.6$ million and $0.4-1.8$ million respectively. The actual values will certainly be higher as these estimates have not taken into account uncommon causes of heart failure ${ }^{1}$. The risk factors of industrialization such as hypertension, coronary artery disease adding up to the conventional ones that are still contributing to heart failure in India such as rheumatic heart disease may probably contribute to this higher prevalence ${ }^{1}$. Heart failure is essentially a disease of old age the proportion of which is increasing in India due to the growing age of its population consequent to the latest advancements in medical field ${ }^{3,4}$ Though chronic heart failure has been the subject of interest among researchers for a long time, studies have lately started focusing on the entity of ADHF in view of the requirement for frequent hospitalisation, the associated morbidity and mortality, and the resultant burden on healthcare expenditure ${ }^{11-15}$. There are sporadic reports that have studied the aetiology of congestive cardiac failure and precipitating factors of ADHF in Indian patients admitted in Indian hospitals ${ }^{18,19}$. The aim of this study is to identify predictors of in-hospital mortality in Indian subset of patients hospitalized for ADHF.

Methods

It is a prospective study carried out in CoimbatoreMedicalCollegeHospital from May 2016 - July 2016. A total of 100 patients who were hospitalized for ADHF were selected for the study. Eligible patients will be enrolled in the study after obtaining informed signed written consent to participate in the same. The principal investigator collects baseline characteristic details of, elicits medical and medications history from and performs complete physical examination in all patients. . All patients were put under continued follow-up during their 
Factors Predicting Mortality In Indian Patients Hospitalized For Acute...

entire hospital stay until study endpoint [discharge after clinical improvement (or) death]. The variables and the in-hospital outcome [discharge after clinical improvement (or) death] were recorded in a confidential database which in turn were subjected to correlation and statistical analysis at the end of the study.

\section{RESULTS}

In our study of 100 patients, a maximum of thirty two patients fall in the 61-70 years age window and it is closely followed by 71-80 years age category that includes thirty patients. The number of patients abruptly drops down to ten in the category of 71-80 years age. The least number of patients is naturally in the 20-30 years category (three in number).

Fig : 1 Relation between age and ADHF

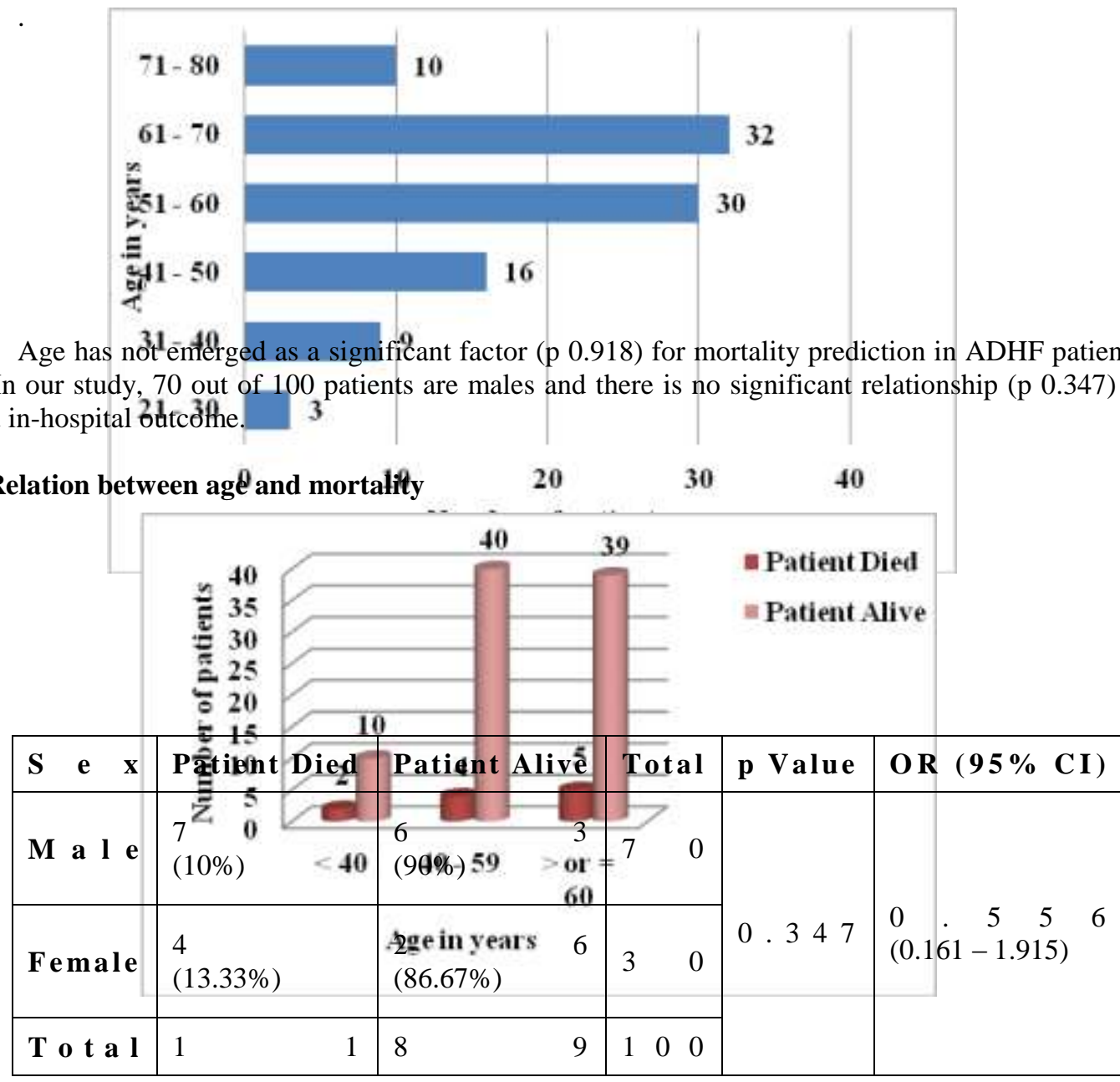

Fig-3 Relation to sex

study. In our study 70 out of 100 patients are males and there is no significant relationship (p 0.347) between sex and in-hospital butcởhe

Fig-2 Relation between age and mortality sex and in-hospital outcome.

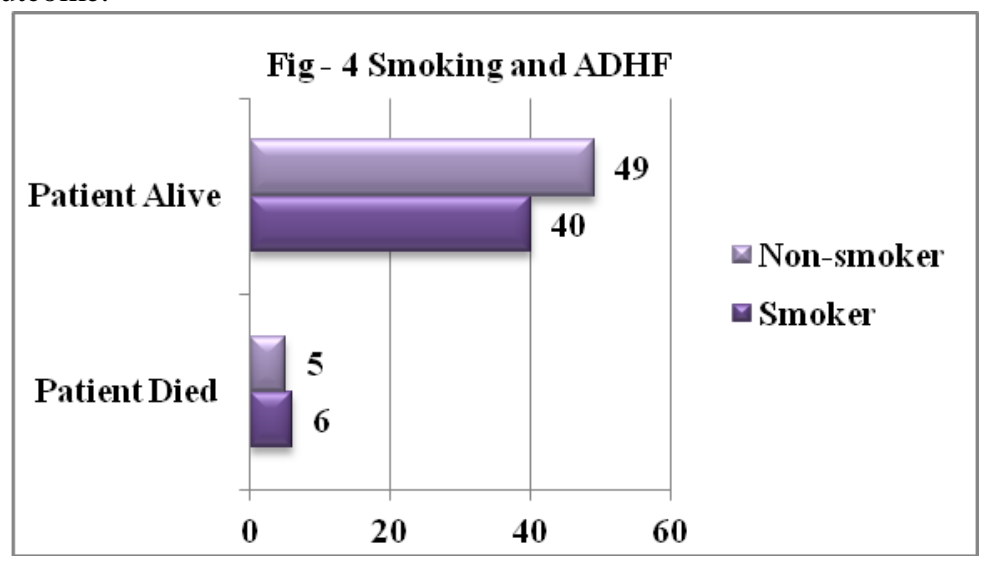


Nearly half of our patients were smokers. Though smoking is an important risk factor for heart failure, it has not emerged significant (p 0.179) for predicting in-hospital mortality in our study.

Fig 5 - NYHA GRADING AND ADHF

\begin{tabular}{|c|c|c|c|c|c|}
\hline N Y H A & $P$ atient Died & Patient Alive & Total & p Value & OR $\left(\begin{array}{lll}95 \% & \text { C I })\end{array}\right.$ \\
\hline Grade 4 & $\begin{array}{l}9 \\
(18 \%)\end{array}$ & $\begin{array}{ll}4 & 1 \\
(82 \%) & \end{array}$ & & \multirow{3}{*}{$\begin{array}{lllll} & 0 & 0 & 1 & 4\end{array}$} & \multirow{3}{*}{$\begin{array}{lcccc}6 & 0 & 0 & 0 & 0 \\
(1.242 & -28.987) & \end{array}$} \\
\hline Grade 3 & $\begin{array}{l}2 \\
(4 \%)\end{array}$ & $\begin{array}{l}4 \\
(96 \%)\end{array}$ & & & \\
\hline T o t a l & 1 & 8 & $\begin{array}{lll}1 & 0 & 0 \\
\end{array}$ & & \\
\hline
\end{tabular}

The NYHA grade among our patients on admission fall into either grade 3 or 4 . Exactly half of them presented with either grade. The proportion of grade 4 patients $(81.8 \%)$ is markedly higher than that of grade 3 patients $(18.2 \%)$ in the dead category. On statistical comparison also, the NYHA grading factor has turned out to be a significant predictor ( $\mathrm{p}$ 0.014) of in-hospital mortality.

Fig - 6 Recurrent vs new onset ADHF

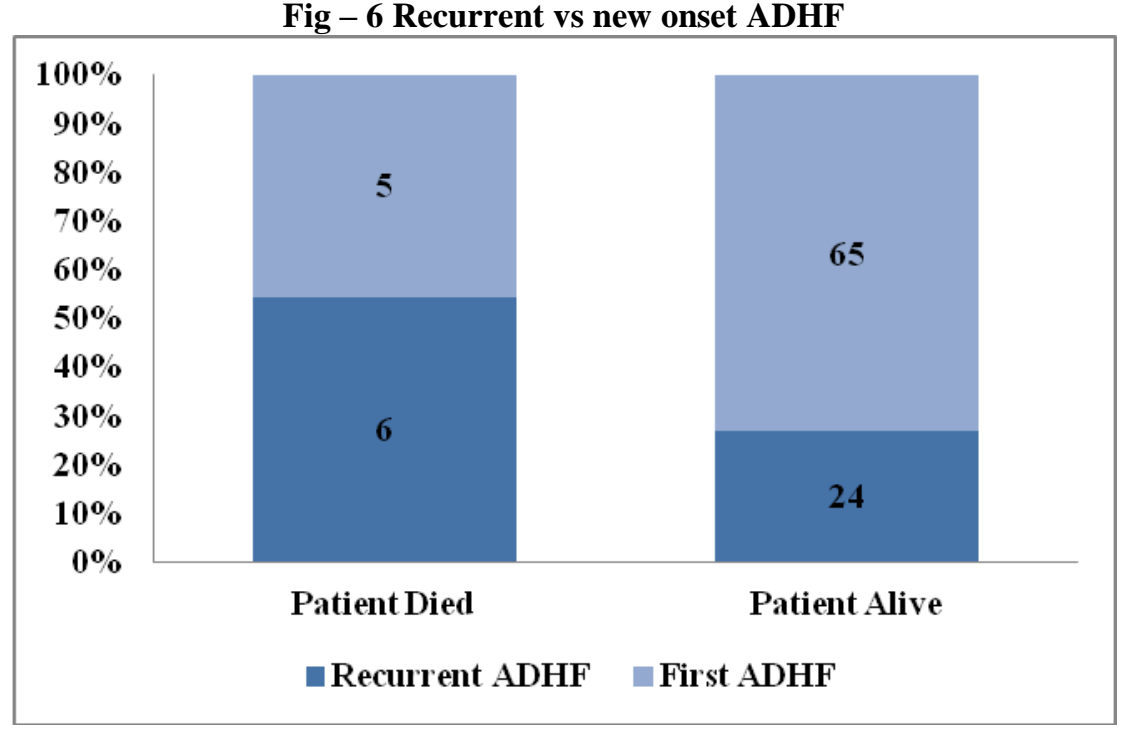

Nearly three fourth of the admissions were new onset where there was no previous history of admission

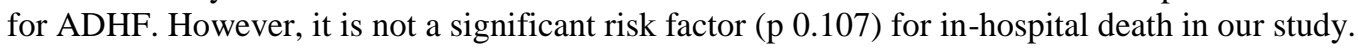

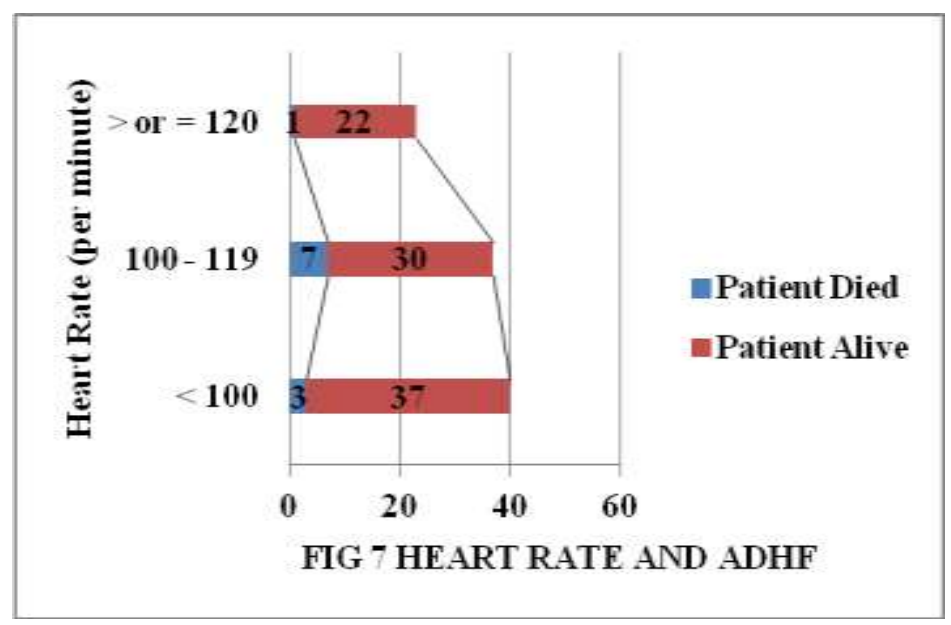

The admission heart rate is not an indicator of in-hospital mortality in our study (p 0.36), though heart rate of less than 120 appears to be associated with better survival rate. 
FIG - 8 : Ejection fraction versus in-hospital mortality

\begin{tabular}{|c|c|c|c|c|c|}
\hline Ejection Fraction (\%) & Patient Died & Patient Alive & Total & p Value & $0 R(95 \% \mathrm{CI})$ \\
\hline $\begin{array}{ll}3 & 0\end{array}$ & $\begin{array}{l}1 \\
(14.28 \%)\end{array}$ & $\begin{array}{l}6 \\
(85.72 \%)\end{array}$ & 7 & \multirow{4}{*}{$\begin{array}{lllll}0 & 0 & 0 & 0 & 4\end{array}$} & \multirow{4}{*}{$\begin{array}{llll}2 & 1 \\
(2.657 & & 7 & 8 \\
178.58) & & \end{array}$} \\
\hline $\begin{array}{llll}30 & 0 & -50\end{array}$ & $\begin{array}{l}8 \\
(12.7 \%)\end{array}$ & $\begin{array}{l}5 \\
(87.3 \%)\end{array}$ & 63 & & \\
\hline 5 & $\begin{array}{l}2 \\
(6.67 \%)\end{array}$ & $\begin{array}{ll}2 & 8 \\
(93.33 \%) & \end{array}$ & 30 & & \\
\hline $\begin{array}{lllll}\mathbf{T} & \mathbf{0} & \mathbf{t} & \mathbf{a} & \mathbf{l}\end{array}$ & 1 & 8 & $\begin{array}{lll}1 & 0 & 0\end{array}$ & & \\
\hline
\end{tabular}

Severity of systolic dysfunction (low ejection fraction) is strongly associated (p 0.004) with death of our patients in hospital. The mortality rate increases from $6.7 \%$ when the EF is more than $50 \%$ to $12.7 \%$ when the EF is between $30 \%$ and $50 \%$ to $14.3 \%$ when the EF is less than $30 \%$. Majority of our patients (63\%) have had moderate LV dysfunction.

Hemoglobin level on admission has shown a strong association (p 0.01) with the hospital outcome in our study. The mortality rates are $2.7 \%, 13.3 \%$ and $66.7 \%$ against the hemoglobin levels of $>$ or $=12$ gm $\%, 9-$ $11.9 \mathrm{gm} \%$ and $<9 \mathrm{gm} \%$ respectively. Three patients had severe anemia out of which two died.

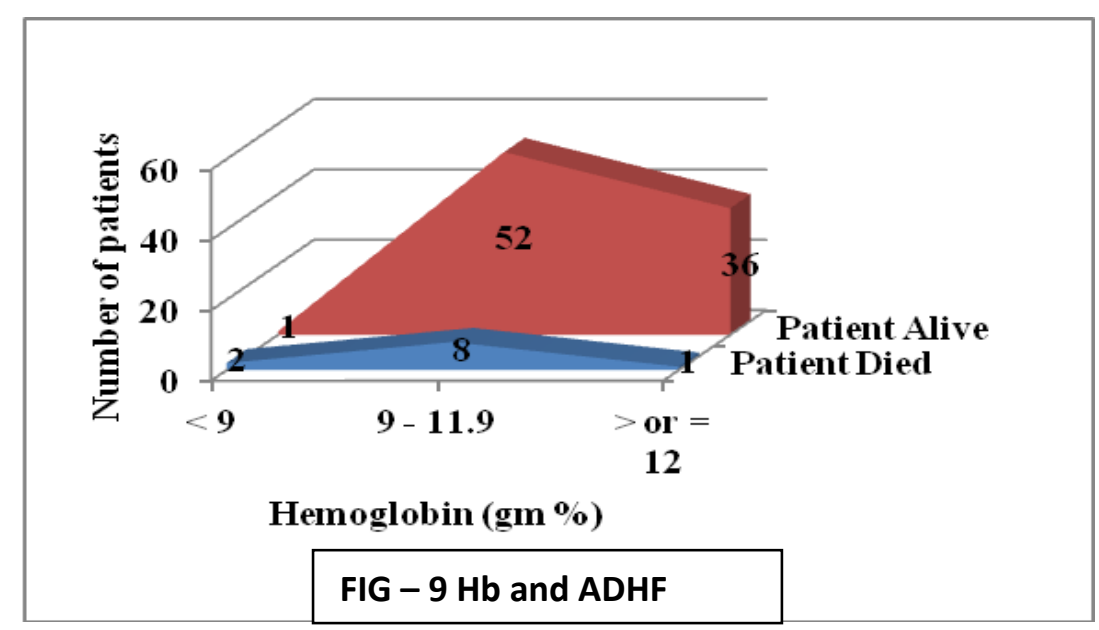

History of dyslipidemia in the past is proved to be insignificant ( $\mathrm{p} 0.663$ ) in predicting in-hospital death in our study. Two thirds of study subjects were known to have dyslipidemia.

\section{FIG - 10: DYSLIPIDEMIA AND ADHF}

Out of hundred patients, eighty nine patients got discharged after improvement of symptoms while eleven patients died in the hospital. Hence the mortality rate in our study is $11 \%$. 


\section{DISCUSSION}

This is a short-term prospective study involving a sample size of hundred patients admitted in our medical college hospital. As discussed earlier, age is an important independent risk factor for heart failure development $^{61}$. In our study, almost two thirds of patients are of the age of $51-70$ years. The less number of patients in above seventy years category may be explained by a pronounced mortality rate due to disease progression, co-existing non-cardiac diseases and simply aging alone. However, the age factor has not affected the outcome of acute heart failure in our study.

Patients with NYHA grade I and II symptoms are least likely to get admitted rather than being managed on an out-patient basis with oral medications. Dyspnea and fatigability due to systemic and pulmonary congestion are the most common symptoms that bring the ADHF patient to medical attention. In ADHERE study which is registry based and includes thousands of patients, eighty nine percent patients presented with dyspnea whereas only thirty one percent of them complained of fatigue ${ }^{16,20}$.

The risk stratification model developed using factors which turned significant in hospital mortality prediction in large retrospective studies on ADHF patients (viz. ADHERE study and OPTIMIZE-HF study) indicated that lower systolic blood pressure on admission would mean a higher mortality rate ${ }^{16,17}$. In our study, lower systolic blood pressure could not discriminate between hospital survivors and non-survivors with statistical significance. A larger sample size might show results similar to those of the above landmark studies, as the current study of hundred samples clearly shows a trend of increasing mortality rate with decreasing systolic blood pressure. It has been found that higher systolic blood pressure levels even in the range above 180 $\mathrm{mm} \mathrm{Hg}$ are not translated to a higher mortality rate. In contrast, a "practically" normal systolic blood pressure in the range of $120-140 \mathrm{mmHg}$ is associated with an increased death rate ${ }^{80}$.

In ADHF patients especially with Ejection fraction has emerged as a significant prognostic indicator in our patients. Seven percent patients had severe LV dysfunction while sixty three percent patients had mild to moderate dysfunction. One third of patients had preserved systolic function and they could represent the subset of diastolic dysfunction causing acute decompensation. OPTIMIZE-HF registry study has found the left ventricular systolic dysfunction as a marker of higher mortality ${ }^{17}$.

The acute heart failure study by Lee et al has found a significant relation between low hemoglobin and adverse hospital outcome ${ }^{83}$. Our study has also found the same with a statistical significance of $\mathrm{p}$ value of 0.01 . Hemodilution due to volume overload in such patients may cause apparently low HB level ${ }^{20}$.

One third of study patients had a history of systemic hypertension while one fourth was found to be diabetic. Nearly half of study patients were known case of coronary artery disease and dyslipidemia was found in two thirds of them. None of them could statistically influence the hospital outcome of study subjects.

The duration of hospital stay before the study endpoint varies widely, ranging from one to thirty four days. Notably, nine out of eleven patients who died have died within three days of admission. The one who died after eight days was a case of thyrotoxic cardiomyopathy due to hyperthyroidism. His underlying disease was uncontrollable and difficult to manage. The one who has died after fourteen days was a case of infective endocarditis complicating rheumatic heart disease (mitral stenosis and mitral regurgidation). He grew staphylococcus aureus and was put on intravenous antibiotics. However, at the end of ten days, he developed myocardial abscess adjacent to the mitral valve apparatus and worsened his failure.

The longest stay with positive outcome was for continuous thirty four days. It was a male patient who had been receiving intravenous antibiotics for his isolated native tricuspid valve endocarditis without any structural lesion. He grew coagulase negative staphylococcus which was sensitive to vancomycin. His failure symptoms were transient and managed successfully with diuretic therapy. Surprisingly, he was not an intravenous drug abuser and had not undergone any invasive medical procedure in the recent past. The second most prolonged stay with a positive outcome was by a young male patient who was newly diagnosed with rheumatic heart disease.

Eleven out of hundred patients died and the mortality rate of our study was eleven percent. The mortality rate of those two landmark studies were $4-4.2 \%$ and $3.8 \%{ }^{16,17}$. Similar studies have reported an inhospital mortality rate of $8.2-8.9 \%$ and $19 \%{ }^{83,84}$. Though all these are registry based retrospective studies, they include very large number of patients in the range of thousands which make their results more reliable and accountable. All these studies have originated from western population. A similar retrospective study in 1949 on Indian patients admitted with cardiac failure reported an in-hospital mortality rate of $27.5 \%{ }^{18}$. Another Indian study has reported an in-hospital death rate of $12.41 \%$, but it included only patients with acute ST elevation MI as the cause of heart failure ${ }^{85}$.Four factors have emerged as significant predictors of hospital outcome in our study, viz. NYHA grade, peripheral edema, ejection fraction, heart rate and hemoglobin. 


\section{CONCLUSION}

Due to the changing pattern of risk factors, the incidence and prevalence of heart failure are on the rise especially in India. Resultantly, the number of hospital admissions required for management of acute decompensated heart failure is also ever increasing. Several mechanisms underlie the relentless progression of chronic heart failure even on optimal treatment, a fact that remains as a major challenge for the medical fraternity. However, in the event of acute decompensated heart failure, there are certain factors that can acutely influence the survival of admitted patients. Unfortunately, a huge lacuna exists in the literature for data on Indian patients. Large-scale Indian studies are needed so that management strategy and guidelines specific for Indian ADHF patients especially in resource restrained settings can be devised.

\section{REFERENCES}

Huffman MD, Prabhakaran D. Heart failure: epidemiology and prevention in India. Natl Med J India. 2010 Sep-Oct; 23(5): 283-8.

Pais P. Xavier D. Heart failure in India: an area of darkness. Natl Med J India. 2011 Jan-Feb;24(1):53.

Lloyd-Jones DM, Larson MG, Leip EP, et al. Lifetime risk for developing congestive heart failure: The Framingham Heart Study. Circulation. 2002;106:3068-72.

National Commission on Population, Government of India. [3 March 2010] Available at http:// populationcommission.nic.in/

Pillai HS, Ganapathi S. Heart failure in South Asia. CurrCardiol Rev. 2013 May;9(2):102-11.

Mohanan PP, Mathew R, Harikrishnan S, et al. Presentation, management, and outcomes of 25748 acute coronary syndrome admissions in Kerala, India: results from the Kerala ACS Registry. Eur Heart J 2012 Sep 7

Xavier D, Pais P, Devereaux PJ, et al. Treatment and outcomes of acute coronary syndromes in India (CREATE): a prospective analysis of registry data. Lancet 2008; 371: 1435-42.

American Heart Association. Heart Disease and Stroke Statistics—2007 Update. Dallas, TX: American Heart Association, 2007.

Cuffe MS, Califf RM, Adams KFJ, et al; Outcomes of a Prospective Trial of Intravenous Milrinone for Exacerbations of Chronic Heart Failure (OPTIME-CHF) Investigators. Short-term intravenous milrinone for acute exacerbation of chronic heart failure: a randomized controlled trial. JAMA. 2002;287:1541-1547.

Felker GM, Leimberger JD, Califf RM, et al. Risk stratification after hospitalization for decompensated heart failure. J Card Fail 2004;10: 460-6

Aronson D, Mittleman MA, Burger AJ. Elevated blood urea nitrogen level as a predictor of mortality in patients admitted for decompensated heart failure. Am J Med 2004;116:466 -73.

Blackledge HM, Tomlinson J, Squire IB. Prognosis for patients newly admitted to hospital with heart failure: survival trends in 12220 index admissions in Leicestershire 1993-2001. Heart 2003;89:615-20.

Clinical Quality Improvement Network Investigators. Mortality risk and patterns of practice in 4606 acute care patients with congestive heart failure. The relative importance of age, sex, and medical therapy. Arch Intern Med 1996;156:1669-73.

Lee DS, Austin PC, Rouleau JL, Liu PP, Naimark D, Tu JV. Predicting mortality among patients hospitalized for heart failure: derivation and validation of a clinical model. JAMA 2003;290:2581-7.

Fonarow GC, Adams KF Jr, Abraham WT, Yancy CW, Boscardin WJ; ADHERE Scientific Advisory Committee, Study Group, and Investigators. Risk stratification for in-hospital mortality in acutely decompensated heart failure: classification and regression tree analysis. JAMA. 2005 Feb 2;293(5):572-80.

Abraham WT, Fonarow GC, Albert NM, et al; OPTIMIZE-HF Investigators and Coordinators. Predictors of in-hospital mortality in patients hospitalized for heart failure: insights from the Organized Program to Initiate Lifesaving Treatment in Hospitalized Patients with Heart Failure (OPTIMIZE-HF). J Am CollCardiol. 2008 Jul 29;52(5):347-56.

Vakil RJ. A statistical study of 1281 cases of congestive cardiac failure or myocardial insufficiency in India. Indian Physician. 1949 Oct; 8(10):281-9.

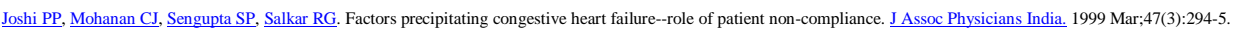

Bonow RO, Mann DL, Zipes DP, Libby P. Braunwald's Heart Disease. A textbook of cardiovascular medicine. 9th edition. Page 487 - 502. 